

University of Pennsylvania

ScholarlyCommons

Management Papers

Wharton Faculty Research

$9-2013$

\title{
Learning From Customers: Individual and Organizational Effects in Outsourced Radiological Services
}

Jonathan R. Clark

Robert S. Huckman

Bradley Staats

University of Pennsylvania

Follow this and additional works at: https://repository.upenn.edu/mgmt_papers

Part of the Business Administration, Management, and Operations Commons

\section{Recommended Citation}

Clark, J. R., Huckman, R. S., \& Staats, B. (2013). Learning From Customers: Individual and Organizational Effects in Outsourced Radiological Services. Organization Science, 24 (5), 1539-1557. http://dx.doi.org/ 10.1287/orsc. 1120.0796

This paper is posted at ScholarlyCommons. https://repository.upenn.edu/mgmt_papers/116

For more information, please contact repository@pobox.upenn.edu. 


\title{
Learning From Customers: Individual and Organizational Effects in Outsourced Radiological Services
}

\begin{abstract}
The ongoing fragmentation of work has resulted in a narrowing of tasks into smaller pieces that can be sent outside the organization and, in many instances, around the world. This trend is shifting the boundaries of organizations and leading to increased outsourcing. Though the consolidation of volume may lead to productivity improvement, little is known about how this shift toward outsourcing influences learning by providers of outsourced services. When producing output, the content of the knowledge gained can vary from one unit to the next. One dimension along which output can vary-a dimension with particular relevance in outsourcing-is the end customer for whom it is produced. The performance benefits of such customer experience remain largely unexamined. We explore this dimension of volumebased learning in a setting where doctors at an outsourcing firm complete radiological reads for hospital customers. We examine more than 2.7 million cases read by 97 radiologists for 1,431 customers and find evidence supporting the benefits of customer-specific experience accumulated by individual radiologists. Additionally, we find that variety in an individual's customer experience may increase the rate of individual learning from customer-specific experience for a focal task. Finally, we find that the level of experience with a customer for the entire outsourcing firm also yields learning and that the degree of customer depth moderates the impact of customer-specific experience at the individual level. We discuss the implications of our results for the study of learning as well as for providers and consumers of outsourced services.
\end{abstract}

\section{Keywords}

customer specificity, experience, healthcare, learning, outsourcing

\section{Disciplines}

Business Administration, Management, and Operations 


\title{
Learning from Customers: Individual and Organizational Effects in Outsourced Radiological Services
}

\author{
Jonathan R. Clark \\ The Pennsylvania State University \\ University Park, PA 16802 \\ Robert S. Huckman \\ Harvard Business School \\ Boston, MA 02163 \\ Bradley R. Staats \\ University of North Carolina at Chapel Hill \\ Chapel Hill, NC 27599-3490
}

Published in Organization Science, Volume 24 Issue 5, Sept-Oct 2013, pp. 1539-1557

\section{Acknowledgments}

We thank management at our field site for their commitment to this work. Frank Levy provided valuable feedback on an earlier draft of this paper. We are grateful to Linda Argote and three anonymous reviewers for helpful comments. All errors are the responsibility of the authors. 


\begin{abstract}
The ongoing fragmentation of work has resulted in a narrowing of tasks into smaller pieces that can be sent outside the organization and, in many instances, around the world. This trend is shifting the boundaries of organizations and leading to increased outsourcing. Though the consolidation of volume may lead to productivity improvement, little is known about how this shift toward outsourcing influences learning by providers of outsourced services. When producing output, the content of the knowledge gained can vary from one unit to the next. One dimension along which output can vary - a dimension with particular relevance in outsourcing - is the end customer for whom it is produced. The performance benefits of such customer experience remain largely unexamined. We explore this dimension of volumebased learning in a setting where doctors at an outsourcing firm complete radiological reads for hospital customers. We examine more than 2.7 million cases read by 97 radiologists for 1,431 customers and find evidence supporting the benefits of customer-specific experience accumulated by individual radiologists. Additionally, we find that variety in an individual's customer experience may increase the rate of individual learning from customer-specific experience for a focal task. Finally, we find that the level of experience with a customer for the entire outsourcing firm also yields learning and that the degree of customer depth moderates the impact of customer-specific experience at the individual level. We discuss the implications of our results for the study of learning as well as for providers and consumers of outsourced services.
\end{abstract}

Key Words: Customer specificity, Experience, Healthcare, Learning, Outsourcing

\title{
1. Introduction
}

The division of labour, by reducing every man's business to some one simple operation, and by making this operation the sole employment of his life, necessarily increases very much the dexterity of the workman - Adam Smith (1776: Section I.1.6).

As noted by Adam Smith (1776) the division of labor has served as a central driver of economic progress. Through increased specialization, individuals and organizations gain knowledge, enabling performance improvement and innovation (Skinner 1974; Newell and Rosenbloom 1981; Argote 1999). The trend toward specialization has been bolstered by institutional and technological change. With respect to the former, the opening of previously closed economies such as Brazil, China, and India have flooded the global labor markets with low-cost talent (e.g., Arora et al. 2001). In terms of the latter, innovations in information and communication technologies have created the opportunity to divide work into smaller pieces and send it around the world to be completed (Zuboff 1988; Autor, Levy and Murnane 2002).

This increasing atomization of work has also reshaped the boundaries of the firm (Levy and Murnane 2004; Levy 2008; Malone, Laubacher and Johns 2011). In a wide variety of settings, from manufacturing to call centers and software services to healthcare services a number of tasks that were 


\section{Learning from Customers}

once done within a focal firm are now contracted out to external service providers. Work may be outsourced for many reasons, but one of the key rationales is to take advantage of the expertise that outsourcers build through volume-based learning (Huckman, Staats and Upton 2009; Narayanan, Balasubramanian and Swaminathan 2009). This idea draws on the concept of the learning curve (Yelle 1979; Argote 1999; Lapré and Nembhard 2010), as outsourcers can combine volume from multiple customers to build experience and thus improve their productivity.

Not only is outsourcing increasing, in part due to the opportunities for volume-based learning, but outsourcing is also changing the industrial landscape in ways that affect how we conceptualize the study of learning. Prior studies of organizational learning highlight that the knowledge gained can vary dramatically from one unit of output to the next based on the characteristics of the work being done (Mishina 1999; Lapré, Mukherjee and Wassenhove 2000; Argote and Miron-Spektor 2011). This tradition of work has highlighted the important, but largely distinct, roles of intraorganizational learning (e.g., Argote and Ophir 2002) and interorganizational learning (e.g., Ingram 2002). While intraorganizational learning has focused on "internal" dimensions that are independent of things outside the firm (e.g., number of units the organization produced, how teams are organized, etc.), interorganizational learning has centered on "external” dimensions (e.g., competitors' experience).

Outsourcing provides a context in which internal and external distinctions are increasingly blurred. For example, as noted previously, outsourcing offers the promise of combining experience from multiple customers to increase aggregate volume. Therefore, a key dimension upon which a unit of output can vary is the end customer to whom it is delivered. However, customer experience - the experience gained with a focal customer - is both an internal dimension (e.g., individual or firm experience gained) and an external dimension (e.g., exposure to a variety of customers). ${ }^{1}$ Though the increased use of outsourcing has led to a rise in the number of customer-supplier interactions, the learning benefits of customer experience remain largely unexamined. An important exception is Ethiraj et al. (2005), which

\footnotetext{
${ }^{1}$ We emphasize that our use of the term "customer experience" refers to experience that a service provider (either an individual or an organization) gains with a focal customer rather than experience that has been accumulated by that customer outside of its relationship with the service provider.
} 


\section{Learning from Customers}

theorizes about, but finds limited evidence of, learning from customer experience in outsourced software projects.

Why might customer experience be an important determinant of learning in service contexts? Due to the interdependent nature of services, the customer and outsourced provider must interact to “coproduce” service output (Larsson and Bowen 1989). By repeatedly interacting with the same customer an individual may learn the customer's standard operating procedures (March and Simon 1993; Boone, Ganeshan and Hicks 2008), improve her communication and mutual adaptation with the customer (Arrow 1974; Weber and Camerer 2003; Ko, Kirsch and King 2005), and learn or transfer new knowledge from the customer (Simonin 1997; Inkpen and Tsang 2007). Therefore, our first area of exploration examines customer learning at the level of individual workers.

In addition to examining the overall effect of individual customer learning, we also consider a key factor that may affect the rate at which individuals learn from focal customer experience - an individual's variety of experience across customers. Drawing on recent work examining learning from varied experience (i.e., related, but different from the focal task, Schilling et al. 2003; Narayanan et al. 2009; Staats and Gino 2012), we consider how experience with other customers may affect an individual's rate of learning with respect to a focal customer. In particular, while prior work does not examine customer experience, its underlying theory suggests that varied experience may have a complementary effect whereby individuals use knowledge gained across areas (in this case, customers) to learn at a faster rate (Hargadon and Sutton 1997; Haunschild and Sullivan 2002; Clark and Huckman 2012). Thus, we ask whether greater variety in the customers with whom an individual works increases her rate of learning from customer-specific experience.

In addition to examining customer learning at the individual level, it is necessary to account for the fact that learning can occur at the level of either the individual or organization (Walsh and Ungson 1991; Kim 1993; Argote and Ingram 2000; Reagans, Argote and Brooks 2005). Therefore, we add to our analysis an examination of the effect of organizational customer experience. Finally, although individual and organizational customer experience may each have independent effects on individual performance, it 


\section{Learning from Customers}

is not clear whether and how they interact to affect performance. This question is important because prior theory suggests that the two types of experience could have a complementary or a substitutive effect on individual performance - in other words, the total effect from individual and organizational customer experience could be greater (a complementary effect) or less (a substitutive effect) than the sum of its individual effects. A complementary effect is possible as individual customer experience could build absorptive capacity (Cohen and Levinthal 1990; Lubatkin, Florin and Lane 2001; Inkpen and Tsang 2007) that helps an individual make better use of the organization's knowledge. Further, greater organizational knowledge may increase the learning an individual gleans from each unit of customer experience as she becomes better able to connect different pieces of information to gain a causal understanding of a situation (Bohn 2005; Bohn and Lapré 2011). Alternatively, the effect may be substitutive to the extent that individual and organizational experience both capture the same underlying knowledge about a customer (Walsh and Ungson 1991; Argote and Ingram 2000) or an individual with more experience becomes more likely to ignore or not use the knowledge of others (Weiss, Suckow and Rakestraw $\underline{\mathrm{Jr}}$ 1999; Schwab 2007). Therefore, our final area of exploration considers whether and how customer experience at the individual level interacts with that at the organizational level to affect individual performance. That is, are these two types of customer experience complements or substitutes?

Likely one of the reasons that customer experience has received little attention in the academic literature is that finding an appropriate research setting is quite difficult. An ideal setting includes not only individuals working for many customers, outcome measures that can be tied clearly to individuals, and a panel of sufficient length to exhibit learning, but also an unbiased data-generation process for matching employees with customers (e.g., a process that does not assign better or faster workers to repeat customers). The setting for this paper, outsourced teleradiology, permits us to address each of these issues. Our data include information from July 2005 through December 2007 on 2,766,209 cases for 1,431 customers read by 97 radiologists working at OutsourceCo (a pseudonym), one of the largest teleradiology firms in the US. Further, as we detail later, OutsourceCo's computer-based algorithm for assigning work reduces concerns about non-random assignment biasing our empirical estimates. 
In the next section, we motivate our hypotheses. We then describe the details of our empirical setting, introduce our data, and discuss our empirical results. Finally, we offer concluding remarks.

\section{Customer Experience and Learning}

That greater cumulative experience leads to improved performance - the learning curve - is one of the more robust phenomena in the study of organizations (Yelle 1979; Argote 1999; Lapré 2011). This relationship has been identified at several levels of analysis - individuals, teams, and firms (e.g., Newell and Rosenbloom 1981; Argote, Beckman and Epple 1990; Pisano, Bohmer and Edmondson 2001). Despite the importance of the volume of cumulative experience, recent work suggests that the specific traits of individual units of experience need to be considered in determining their contribution to learning (Mishina 1999; Lapré et al. 2000; Argote and Miron-Spektor 2011). In the next section we explore why one of these traits - the customer to whom a service is provided - may prove important in determining learning and performance in a focal task.

\subsection{Customer Experience for Individual Providers}

In settings such as outsourced services, where tasks are completed for many different customers, working with a specific customer may lead to better performance due to improved coordination and knowledge transfer. With respect to coordination, due to the interdependent nature of services, the customer and outsourced provider must interact to "coproduce" many services (Larsson and Bowen 1989). For example, in outsourced radiology, a technician at a hospital takes the image while a doctor at the hospital requests that the outsourced radiologist read the image (and may provide specific, written instructions with the read request) and the actions of both of these individuals at the customer affect the outsourced radiologist's ability to complete her work.

Generalizing this example from our setting, one finds several reasons why repeated interaction with a given customer may improve an individual's ability to provide outsourced services to that customer. First, repeated experience with a customer may provide an outsourcer with insight into that customer's standard operating procedures and may allow more efficient execution of work (March and 


\section{Learning from Customers}

Simon 1993; Boone et al. 2008). Second, different organizations often use varying language to describe similar phenomena (Arrow 1974; Weber and Camerer 2003; Ko et al. 2005). As an individual provider gains experience with a specific customer, she may be better able to communicate with employees at that customer (in addition to any specific individuals with whom she may work repeatedly), aiding in the transfer of knowledge (Szulanski 1996; 2000). In our empirical setting such improved communication is likely to manifest itself in written messages, rather than verbal ones. Prior work highlights the challenge in successfully coding and decoding written messages (Arrow 1974). Third, given that customers are often reticent to share information with an outsourced provider (Metiu 2006), repeated interaction may increase trust and build relationship-specific capital (Uzzi 1997; Lubatkin et al. 2001; McEvily, Perrone and Zaheer 2003). Again, this effect could occur between an individual at the outsourced provider and an individual at the customer as they work together; or more generally when an individual at the outsourced provider works with multiple people at a customer. For example, with repeated experience a referring physician may be more likely to include additional information in the request that is sent to the radiologist (such as guidance on the specific anatomy to examine). These latter two points-communication and information sharing - are particularly salient in outsourced radiology where the coordination between parties may not be sequential, but rather reciprocal (i.e., requiring ongoing, mutual adjustments, Thompson 1967; Argote 1982), across multiple reads.

While theory suggests that prior experience with a customer may improve coordination and knowledge transfer, it is not clear if this theory will translate to the teleradiology context we study, and to outsourcing more generally. A common claim is that activities that are ideal candidates for outsourcing are "commoditized", thus suggesting that aspects such as customer characteristics, should not impact the relationship between experience and performance. Commoditized activities tend to be well-specified, or codified, which allows clear contracts to be written between outsourcers and customers and allows process and product specifications to be transferred easily between those parties. For example, clear standards can be set for the formulation of chemical compounds or the assembly of cellular phones, both of which are activities that are often outsourced. 
In contrast to this view, Steinbrook (2007) suggests that experience with a customer may play a significant role in determining teleradiology performance, noting:

Physicians may be less likely to know the radiologists who read their patients' studies, and there may be more opportunities for miscommunication and misunderstandings. A teleradiologist will often have no information about the patient beyond that contained in the study requisition.

Wachter (2006) in quoting the CEO of one of the largest teleradiology firms, echoes this perspective in describing how even in teleradiology, as compared to on-site interpretation, the radiologist and doctor interaction is maintained: “'You can’t reach over and slap [the radiologist] on the back, but every other aspect of the interaction is preserved."

The claim that radiological interpretation benefits from familiarity with referring physicians (i.e., customers) suggests that there may be significant benefits derived from customer experience in a teleradiology setting. To examine fully the customer specificity of individual experience, however, it is necessary to consider an additional dimension of experience. Namely, just as it is possible to gain customer experience, it is also possible to gain experience specific to a given knowledge domain. Prior work studying software development finds evidence for such domain specificity (Boh, Slaughter and Espinosa 2007; Kang and Hahn 2009). In some cases, the choice of domain may limit activity to a specialized population of workers. For instance, an individual suffering from cancer in the brain is likely to visit a neurologist or neurosurgeon, while an individual suffering from prostate cancer will visit a urologist. In many other contexts, however, the same worker may complete the activity regardless of the domain examined. For example, in this study a unit of output is a radiological read, which many radiologists can perform regardless of whether the study was conducted on different body parts such as the head, pelvis, or abdomen.

Customer-domain experience may have a greater effect on individual performance than does customer experience in other domains (though we expect both to have a greater effect on performance than the final category of experience with other customers). Different domains have domain-specific terminology and practices. These practices may vary across hospitals making the customer-domain 
experience most relevant for performance for a focal task. Further, given the need for domain specialization most hospitals are divided according to domain. For example, the department of cardiology has primary responsibility for heart conditions, and the department of orthopedics is tasked with musculoskeletal issues. Therefore, when executing tasks for a given customer-domain combination, an individual radiologist in our sample is likely to work with the same sub-group of referring physicians within a hospital and build the important ties mentioned above. Given all of these factors, we offer the following related hypotheses:

HYPOTHESIS 1a: An individual's customer, domain experience has a more positive effect on performance of a focal task than experience gained from the same customer in different domains.

HYPOTHESIS 1b: An individual's customer, domain experience has a more positive effect on performance of a focal task than experience gained from all other customers. $^{2}$

\subsection{Variety in Individual Customer Experience}

Hypothesis 1 details why we expect customer-specific experience to have a greater effect on individual performance than all other experience. In addition to understanding the main effect of customer experience on individual performance, related work on specialization and variety in task experience (Boh et al. 2007; Narayanan et al. 2009) suggests that it is important to examine also the interaction effects of different types of experience (Clark and Huckman 2012; Staats and Gino 2012). In other words, although specialized experience (in our case, customer experience) may have a greater direct effect than varied experience on individual performance of a focal task, varied experience may prove useful in increasing the learning derived from specialized experience (Lapré and Nembhard 2010).

There are several reasons why varied experience (in this case, the distribution of experience across other customers) may increase an individual's rate of learning from customer experience in the focal task. When working for different customers, an individual may identify best practices from one customer that can be transferred to another (Hargadon and Sutton 1997; Bohn 2005; Huckman and Staats

\footnotetext{
${ }^{2}$ For simplicity and clarity, in the remainder of the paper we refer to an individual's customer-domain experience and customer experience interchangeably.
} 
2011) or may recognize higher-order principles that affect multiple customers (Schilling et al. 2003; KC and Staats 2012). Literature on varied experience also suggests, that by working across multiple areas, an individual may change her learning process by reconsidering underlying assumptions, processing data in new ways, and searching for deeper, more-causal explanations - all of which may lead to learning at a faster rate (Piaget 1963; Ellis 1965; Haunschild and Sullivan 2002).

Alternatively, individual variety in experience may slow individual learning within a focal customer. For example, greater variety in experience could prove cognitively distracting (cf, Monsell 2003) making it harder for an individual to learn from her present experience. However, prior work suggests that over time the distraction effects of variety are likely outweighed by its benefits (Staats and Gino 2012). We therefore hypothesize:

HYPOTHESIS 2: Individual variety in customer experience will have a positive, moderating effect on the relationship between individual customer experience and the performance of a focal task.

\subsection{Customer Experience throughout the Organization}

Although individuals complete tasks in an organization, individuals may also learn from the experience that the organization accrues (Argote 1999; Reagans et al. 2005; Lapré and Nembhard 2010). Organizational experience can improve individual performance in multiple ways. With repeated experience, an organization may develop operating procedures and routines for completing work (Nelson and Winter 1982). These routines may be captured explicitly in standardized work practices (Staats, Brunner and Upton 2011) or enterprise information technology systems (Brunner 2009) or, alternatively, may be captured tacitly in the norms and culture of an organization (Nonaka 1994; Nonaka and Takeuchi 1995). Over time the organization may build a capability, defined as the consistent ability to do that which is intended, out of these routines (Dosi, Nelson and Winter 2000; Hayes et al. 2005).

Organizational experience may also improve individual performance through better problem solving. Depending on the setting, an individual may learn by watching others complete the same task (Bandura 1977; Gino et al. 2010; KC and Staats 2012). Additionally, organizational experience creates a 
reservoir of knowledge (Walsh and Ungson 1991; Argote and Ingram 2000) and individual members may be able to draw on that knowledge by seeking the help of others when they encounter difficulties (Lee 1997; Hofmann, Lei and Grant 2009).

In this study we focus on organizational experience gained with a specific customer. There are several reasons why this type of experience may aid individual performance. The organization may use the knowledge gained from its experience to develop focused practices to serve a customer. For example, in one context, Indian software services, outsourcers often set up offshore delivery centers (ODC) to execute work for customers (Arora et al. 2001). One objective of an ODC is to capture customer learning across projects. Also, in contexts where customers are involved in the production of a service (Larsson and Bowen 1989), for example, healthcare or software, the customer may also learn from its experience with the outsourcer, changing its own practices to work more effectively. This mutual adaptation may lead to organizational-level learning from customer experience. Overall, we hypothesize:

HYPOTHESIS 3: $\quad$ An organization's customer experience has a positive effect on individual performance of a focal task.

\subsection{Individual and Organizational Customer Experience: Complements or Substitutes?}

As outlined in Hypotheses 1a, 1b, and 3, both individual customer experience and organizational customer experience are likely to have independent beneficial effects on individual learning and performance. An important and unexamined question is how these two types of experience interact with one another to affect individual performance. The answer to this question has meaningful theoretical consequences, in part because theory suggests that individual- and organizational-level customer experience could be either complements or substitutes.

The argument in favor of complements rests on the theoretical idea of absorptive capacity - it often takes one's own knowledge to utilize fully the knowledge held by others (Cohen and Levinthal 1990). This is because an individual's existing knowledge helps her not only to identify, acquire, and understand external knowledge, but also allows her to transform and exploit that knowledge (Mowery and Oxley 1995; Zahra and George 2002). Through identifying, acquiring and understanding external 


\section{Learning from Customers}

knowledge, an individual is likely to see a direct effect of organizational experience on individual performance (Hypothesis 3).

It is in the transformation and exploitation of external knowledge that the potential complementarity between individual and organizational customer experience arises. The literature on alliances finds that absorptive capacity may not be just a general characteristic but also a dyadic one between two partners (Lane and Lubatkin 1998; Mowery, Oxley and Silverman 2002). Similarly, if an individual's customer experience builds absorptive capacity in understanding a customer, that individual may be better positioned to transform and use the knowledge arising from her organization's experience with that same customer (Lubatkin et al. 2001). When an individual completes a task for a customer, she has an opportunity to learn about that customer. However, learning requires making connections between different pieces of information to gain a causal understanding of a situation (Bohn 2005; Bohn and Lapré 2011). When completing a task, an individual typically does not have complete knowledge and understanding of the situation. Therefore, organizational experience with a customer might help fill in missing information. Further, learning and innovative solutions often arise from combining existing knowledge in new ways (Fleming and Sorenson 2004). Together, these conditions suggest that individual and organizational experience with a particular customer can be mutually reinforcing.

Alternatively, individual- and organizational-level customer experience may act as substitutes. In other words the joint benefit of individual and organizational experience may be less than the sum of the two individual effects (Schwab 2007). First, it is possible that the knowledge gained from either individual or organizational experience may capture the same underlying information. If information is at least partially redundant, then either type of experience, by itself, could be sufficient to improve performance (Walsh and Ungson 1991; Argote and Ingram 2000). Second, if adaptation by the customer is the key driver of learning and improved performance (Lubatkin et al. 2001; Inkpen and Tsang 2007) then either individual or organizational customer experience could trigger such change, causing individual and organizational experience to have similar effects on learning. Finally, the salience or increased understanding from individual knowledge may affect an individual's use of knowledge held at the 
organizational level (Levinthal and March 1993). Namely, prior research shows that as an individual has increased experience, she may be more likely to ignore the knowledge of others (Weiss et al. 1999;


may have a substitutive effect on individual performance.

Given the compelling motivation for either a complementary or substitutive interaction, we specify competing hypotheses as follows:

HYPOTHESIS 4A: Organizational customer experience will have a positive, moderating effect (complementary interaction) on the relationship between individual customer experience and the performance of a focal task.

HYPOTHESIS 4B: $\quad$ Organizational customer experience will have a negative, moderating effect (substitutive interaction) on the relationship between individual customer experience and the performance of a focal task.

\section{Setting - Outsourced Teleradiology Services}

Radiology is a medical specialty that involves performing and interpreting imaging studies (e.g., x-ray, computed tomography (CT), magnetic resonance imaging (MRI), ultrasound, and nuclear medicine) to diagnose and treat disease. Historically, both the performance and interpretation of radiological studies occurred within the boundaries of a single provider organization, such as a hospital or radiology group practice. During the past decade, however, provider organizations have experienced a dramatic increase in the volume of radiological studies they perform and, therefore, need to interpret. Between 1999 and 2004, cumulative growth in the volume of all physician services per Medicare ${ }^{3}$ beneficiary was $31 \%$; analogous figures for radiological services, however, were much larger at $62 \%$ across all radiological services, $112 \%$ for nuclear medicine, and 140\% for non-brain MRI (Steinbrook 2007). This growth is potentially due to several factors, the most prominent being technological

\footnotetext{
${ }^{3}$ Medicare is the United States' federal health insurance program for individuals 65 years and older and those falling into a small number of other specific categories.
} 


\section{Learning from Customers}

advancements in imaging (Levy and Goelman 2005; Steinbrook 2007) and the practice of "defensive medicine" to avoid the threat of malpractice liability (Studdert et al. 2005).

The rapid growth in imaging studies has outpaced growth in the supply of radiologists to read them. In addition, hospitals, particularly smaller community facilities, are not able to find or afford employed radiologists to provide "off-hours" coverage for the interpretation of the growing number of studies performed on an emergency basis. This dual need for additional capacity and 24-hour coverage has fueled demand for teleradiology - the computerized transmission and interpretation of radiological studies outside the physical locations in which those studies are conducted. Teleradiology services can be provided either by a hospital or practice's employed radiologists (e.g., from their homes outside of traditional business hours) or by an outsourcer either in the United States or abroad. ${ }^{4}$ Surveys of over 1,900 radiologist practices indicate that between 2003 and 2007, the percentage of practices outsourcing some portion of their radiology services nearly tripled from $15 \%$ to $44 \%$ (Lewis, Sunshine and Bhargavan 2009). It is reasonable to expect that this percentage has grown in recent years due to continued increases in volume and technological advances in imaging.

The data for our study were obtained from OutsourceCo, one of the largest U.S.-based providers of outsourced teleradiology services. OutsourceCo employs radiologists who are board-certified and licensed to practice radiology in the United States. Approximately 55\% of its radiologists are based in the United States, working from either their homes or one of several reading centers owned by OutsourceCo. The remainder is based overseas, again working either from home or a reading center. OutsourceCo has more than 1,400 client sites - mostly hospitals and group radiology practices - across the United States.

Most of the studies interpreted by outsourced teleradiology providers can be categorized based on the technology used to generate them. The most common technologies used in these studies are:

\footnotetext{
${ }^{4}$ Some of the leading providers of outsourced teleradiology services are NightHawk Radiology, Teleradiology Solutions, and Virtual Radiologic. All of these companies have radiologists in the United States and most also have radiologists based in other countries who are able to work during their standard business hours to interpret "offhours" studies from the United States. For further discussion of these outsourced models, see Wachter (2006).
} 
- X-ray: The oldest radiologic technology, X-ray involves the use of ionizing electromagnetic radiation to view various parts of the human anatomy. X-ray accounts for 4\% of OutsourceCo's case volume.

- Computed tomography (CT): Introduced in the 1970s, CT allows for the generation of threedimensional images of various anatomical regions by combining a series of two-dimensional images taken around an axis of rotation. CT accounts for $84 \%$ of OutsourceCo's case volume.

- Magnetic resonance imaging (MRI): In contrast to X-ray and CT, MRI relies on a magnetic field rather than ionizing radiation to generate images of various anatomical regions. In addition to reducing exposure to radiation, MRI also provides greater contrast between various soft tissues in the body than can be obtained with either X-ray or CT. MRI accounts for $1 \%$ of OutsourceCo's case volume.

- Ultrasound: Ultrasound involves the use of high-frequency acoustics to obtain real-time images of various parts of the body. It does not involve the use of ionizing radiation and tends to be cheaper and more portable than both CT and MRI. One of the most common uses of ultrasound is for routine obstetric diagnosis and monitoring. Ultrasound accounts for $10 \%$ of OutsourceCo's case volume.

- Nuclear medicine: Nuclear medicine involves combining radioactive isotopes with other pharmaceutical compounds to examine cellular function and physiology. Nuclear medicine accounts for $1 \%$ of OutsourceCo's case volume.

Customers upload studies performed at their hospitals or offices to OutsourceCo's proprietary system. Each study is initially processed by an administrative assistant, who assigns it to the queue of an eligible radiologist who is on duty at that time. For any given study, an eligible radiologist is one who is trained in the relevant anatomical area (e.g., head, spine, and abdomen) and technology (e.g., CT, MRI, nuclear medicine). In addition, an eligible radiologist must be licensed to practice medicine in the state- and be a member of the medical staff of the hospital — where the image was generated. Given these requirements, the typical radiologist at OutcourceCo is eligible to practice in over 35 states and at more than 400 hospitals. During our study period, more than $90 \%$ of OutsourceCo's radiologists performed reads using each of the technologies described above. In terms of anatomical specialties, all but one of OutsourceCo's 
radiologists performed reads in at least 7 of the 11 possible anatomical areas and $94 \%$ performed reads in at least 10 such areas. $^{5}$

Conditional on a radiologist being on duty and appropriately trained and licensed, the assignment of cases to radiologists is random. A radiologist completing tasks more quickly will have the opportunity to complete more tasks, but the OutsourceCo system does not assign "more-important" tasks to specific doctors. Once a case has been read, the radiologist completes a report that is checked for clerical and administrative completeness by the assistant before being forwarded to the customer.

\section{Data and Empirical Strategy}

\subsection{Data}

Images arriving at OutsourceCo's central image distribution system are assigned primarily on a reading radiologist's current workload relative to her capacity. We note that, within the universe of customers, domains, and technologies for which a radiologist is eligible to provide services, the customer, domain, and technology characteristics of an image are not factored into the assignment algorithm. Our data include information on every radiological image assigned to OutsourceCo radiologists between July 2005 and December 2007. Data include unique identifiers for each radiologist and each ordering customer; the body part imaged (i.e., domain); the technology used to take the image; and time stamps for when a case was received and when the radiologist finished reading it. The raw data contains an observation for each image, though a single case (i.e., one patient) may consist of multiple images. Time stamps are case specific and not image specific. Accordingly, we are only able to calculate estimated read times at the case level. To do so, we collapse the image-level observations to case-level observations, retaining indicators for body location, technology, and number of images in addition to unique identifiers for the reading radiologist and customer. The resulting data set includes 2,766,209 cases read by 97 radiologists for 1,431 customers over the 30 -month period covered by the data.

\footnotetext{
${ }^{5}$ Anatomical specialties observed in our dataset include: abdomen, body, brain, breast, cardiovascular, chest, gastrointestinal/genitourinary, head and neck, musculoskeletal, obstetrics, spine and other.
} 


\subsection{Dependent Variable}

Our outcome of interest is the length of time it takes a radiologist to read a case (READTIME). Time to completion is not only a commonly used performance measure in the learning literature (Pisano et al. 2001; Reagans et al. 2005), but it is also an important measure for operational performance in this context for both OutsourceCo (which garners greater productivity from its radiologist labor) and its customers (who receive more timely response for what are often emergency cases). In theory, an additional performance variable is performance quality; however, only $0.3 \%$ of our cases are characterized by a "discrepancy". Given this low rate and the fact that many of these discrepancies result from a need for clarification rather than deficient performance, we are not able to examine quality performance in this study.

To calculate READTIME, we rely on information about when each case is received (time in) and when the radiologist completes the read (time out). Time-in, however, does not necessarily represent when the radiologist begins reading a case. For example, when a case is assigned to a reading radiologist, it enters his queue. The radiologist may read his queue in the order received or may choose to rearrange images to better suit his workflow. Therefore, we make two key assumptions, derived from our discussions with personnel at OutsourceCo, to calculate READTIME. First, we assume that during a radiologist's work shift, time out for the prior case is a reasonable approximation for the start time of the current case. Radiologists work on cases sequentially and do not start a new case until they have finished the prior case. Second, we assume that any elapsed time between the time out of the current case and the time out of the prior case greater than 30 minutes represents a "break" between a radiologist's shifts. The 30-minute break window was determined based on the data. Specifically, we examined the average and standard deviation of the difference between the time out of a radiologist's current read and the time out of the prior read. The 30-minute cutoff is approximately equivalent to the average plus four standard deviations. Nevertheless, we examine the robustness of our results to shorter and longer break windows. 
Using these assumptions, we partition each radiologist's list of cases into shifts using the break window described above. For each radiologist and each shift, cases are ordered by time out and READTIME is calculated as follows:

(1) First case of a shift: read time equals time out minus time in

(2) All subsequent shift cases: read time equals time out for the current case minus time out for the prior case

\subsection{Independent Variables}

To examine our hypotheses we split the prior experience of individual radiologists into segments that enable us to estimate the learning benefit of customer-domain experience relative to all other types of experience. As a baseline model, we divide a radiologist's prior experience into two categories. IndvlCustomer represents what we term individual customer experience, the cumulative number of prior cases read by a radiologist for the customer of the current case. IndvlOtherCustomer represents the cumulative number of prior cases read by a radiologist for all customers other than the customer of the current case. We next divided experience within each of the two customer categories by domain to create four categories of experience. These measures consist of components that are unique to the customer and the domain, customer but not the domain, domain but not the customer, or neither category. Domains are defined based on the body-part imaged and are categorized consistent with the subspecialties recognized by the American College of Radiology and the Radiological Society of North America and with the way radiology departments are organized in typical academic medical centers in the United States. These categories include: Abdomen, Body (combination images), Brain, Breast, Cardiovascular, Chest, Gastrointestinal/Genitourinary, Head and Neck, Musculoskeletal, Obstetrical, and Spine.

Based on these categories, IndvlCustomerDomain represents the cumulative number of prior cases read by a radiologist in the domain, and for the customer, of the current case; IndvlCustomerOther Domain represents the cumulative number of prior cases (outside the domain of the current case) read by a radiologist for the customer, of the current case; IndvlOtherCustomerDomain represents the total cumulative number of prior cases for a given radiologist that match the domain (e.g., Body, Chest, Spine, 


\section{Learning from Customers}

etc.), but not the customer, of the current case; and IndvlOtherCustomerOtherDomain represents the cumulative number of prior cases read by a given radiologist in all domains and for all customers other than those of the current case. Figure 1 provides an illustration of how these measures relate to one another. Having constructed these four, collectively exhaustive combinations of customer and domain experience, we use them to test Hypotheses $1 \mathrm{a}$ and $1 \mathrm{~b}$.

$* * * * * * * * * * * * * * * * * * * * * * * * * * * * * * * * *[$ Insert Figure 1]

To test Hypothesis 2, we examine the extent to which the experience of a reading radiologist is distributed across a variety of customers. Specifically, we measure the degree to which a radiologist's cumulative volume prior to the current case is concentrated by customer. To do so, we use a Herfindahlstyle index of customer concentration. Thus IndvlCustomerFocus is produced by first measuring, for each case, the share of that radiologist's prior volume devoted to each customer. These volume shares are then squared and summed, producing a measure for which higher values indicate a greater degree of customer concentration (i.e., less variety). The interaction of this measure with IndvlCustomerDomain allows a test of Hypothesis 2.

To test Hypothesis 3, we create a variable, OrgCustomer, which captures the depth of OutsourceCo's experience with a particular customer. Specifically, OrgCustomer is the total number of prior cases a customer has sent to OutsourceCo. To distinguish this variable from the customer experience of the current reading radiologist (and to facilitate the interactions necessary to test Hypothesis 4), we subtract the current reading radiologist's experience with the current customer. Thus, OrgCustomer is the cumulative number of prior cases the current customer has sent to OutsourceCo, less the current radiologist's cumulative experience (across all domains) with that customer. In our models, we examine this variable in both a linear and discrete form. The discrete form consists of three categories representing the linear variable split into thirds: OrgCustomer1, OrgCustomer2, and OrgCustomer3. This categorical version is intended to facilitate the interpretation of the interactions with radiologist experience and to reduce the correlation present between OrgCustomer and IndvlCustomerDomain (correlation $=0.64$ ). Specifically, the correlation between IndvlCustomerDomain and OrgCustomer2 and OrgCustomer3 is 
0.26 and 0.46 , respectively. These notably lower levels of correlation increase our confidence that the thirds of OrgCustomer and the continuous IndvlCustomerDomain are in fact capturing different characteristics when we interact them to test Hypothesis 4. Table 1 contains summary statistics and correlations for our key variables of interest.

$* * * * * * * * * * * * * * * * * * * * * * * * * * * * * * * * *[$ Insert Table 1]

\subsection{Empirical Models}

To examine the impact of various types of experience on individual performance, we use ordinary least squares regression to estimate a series of exponential learning curve models. We rely on the exponential form of the learning curve to examine our hypotheses because as Lapre and Tsikriktsis (2006) have demonstrated, "for the exponential form, accounting for prior experience is a nonissue —omission of prior experience will not bias learning-rate estimates." Given that our data only includes the experience of radiologists with OutsourceCo between July 2005 and December 2007-and no experience accumulated prior to that window - the exponential form avoids the bias problem that would arise with the power form.

\section{Individual Customer Experience}

To test for customer specificity at the individual level (Hypotheses 1a and 1b), we estimate the following:

$\ln \left(\right.$ READTIME $\left.E_{\text {hijt }}\right)=$

$\alpha_{t}+\gamma_{h i}+\beta_{1}$ IndvlCustomerOtherDomain $_{\text {hij }}+\beta_{2}$ IndvlCustomerDomain $_{\text {hij }}+\beta_{3}$ IndvlOtherCustomerDomain $_{i j}+$ $\beta_{4}$ IndvlOtherCustomerOtherDomain $_{i j}+\beta_{5}$ IndvlCustomerFocus $_{i j}+\beta_{6}$ Backlog $_{i j}+\varphi_{1} X_{j}+\varepsilon_{\text {hijt }}$

where $\gamma_{h i}$ and $\alpha_{t}$ are fixed effects for customer $h$-radiologist $i$ pairings and year $t$, respectively. The former captures time-invariant characteristics of customer-radiologist pairs that may influence $R E A D T I M E_{h i j t}$; the latter captures changes in the average value of $R E A D T I M E_{h i j t}$ for the sample over time. $B a c k \log _{\mathrm{ij}}$ represents the number of cases in the queue of radiologist $i$ when reading case $j . \mathrm{X}_{j}$ represents a vector of characteristics for individual case $j$, including binary indicators for the technology employed and the knowledge domain addressed to control for differences in the average read time across these 


\section{Learning from Customers}

dimensions. The model also includes the number of images for case $j$ to capture the amount of information a reading radiologist must consider to complete the current case. IndvlCustomerOtherDomain $_{h i j}, \quad$ IndvlCustomerDomain ${ }_{h i j}, \quad$ IndvlOtherCustomerDomain ${ }_{i j}$, IndvlOtherCustomerOtherDomain $_{i j}$ and IndvlCustomerFocus $i_{i j}$ are as described previously, with IndvlCustomerDomain $_{h i j}$ the key variable of interest. Given that negative values of $\beta_{1}, \beta_{2}, \beta_{3}$ and $\beta_{4}$ are associated with better performance (i.e., shorter read times), Hypothesis 1a predicts that $\beta_{2}$ will be less than $\beta_{1}$ and Hypothesis $1 \mathrm{~b}$ predicts that $\beta_{2}$ will be less than $\beta_{3}$, and $\beta_{4}$.

\section{Organizational Customer Experience}

To test Hypothesis 3 related to the benefits of an organization's depth of experience with a particular customer, we examine the following models:

$$
\begin{aligned}
& \ln \left(\text { READTIME } E_{\text {hijt }}\right)=\alpha_{t}+\gamma_{h i}+\delta_{1} \text { OrgCustomer }_{h j}+\varphi_{1} X_{j}+\varepsilon_{\text {hijt }} \\
& \ln \left(\text { READTIME } E_{\text {hijt }}\right)=\alpha_{t}+\gamma_{h i}+\delta_{2} \text { OrgCustomer }_{h j}+\delta_{3} \text { OrgCustomer }_{h j}+\varphi_{1} X_{j}+\varepsilon_{\text {hijt }}
\end{aligned}
$$

Where $\gamma_{h i}, \alpha_{t}$ and $X_{\mathrm{j}}$ are as previously described. In (2), OrgCustomer enters in linear form; in (3), it enters in discrete thirds (with OrgCustomerl omitted).

\section{Customer Experience Interactions}

To examine Hypotheses 2 and 4, we interact each segment of the radiologist's prior customer experience with either an individuals' variety of customer experience (IndvlCustomerFocus) or the customer's depth of interaction with OutsourceCo (OrgCustomer). This involves merging the variables from (3) with those from (1) above and creating the appropriate interactions as follows:

$\ln \left(R E A D T I M E_{\text {hijt }}\right)=$

$\alpha_{t}+\gamma_{h i}+\beta_{1}$ IndvlCustomerOtherDomain $_{h i j}+\beta_{2}$ IndvlCustomerDomain $_{h i j}+\beta_{3}$ IndvlOtherCustomerDomain $_{i j}+$ $\beta_{4}$ IndvlOtherCustomerOtherDomain $_{i j}+\beta_{5}$ IndvlCustomerFocus $_{i j}+\delta_{2}$ OrgCustomer $_{h j}+\delta_{3}$ OrgCustomer $_{h j}+$ $\vartheta_{1}\left(\right.$ IndvlCustomerOtherDomain $_{\text {hij }} *$ IndvlCustomerFocus $\left._{i j}\right)+\vartheta_{2}\left(\right.$ IndvlCustomerDomain $_{\text {hij }} *$ IndvlCustomerFocus $\left._{i j}\right)+$ $\vartheta_{3}\left(\right.$ OrgCustomer $_{h j} *$ IndvlCustomerOtherDomain $\left.{ }_{\text {hij }}\right)+\vartheta_{4}\left(\right.$ OrgCustomer $_{h_{j}} *$ IndvlCustomerOtherDomain $\left._{\text {hij }}\right)+$ $\vartheta_{5}\left(\right.$ OrgCustomer $_{h j} *$ IndvlCustomerDomain hij $)+\vartheta_{6}\left(\right.$ OrgCustomer $_{h j} *$ IndvlCustomerDomain $\left._{\text {hij }}\right)+\beta_{6}$ Backlog $_{i j}+$ $\varphi_{1} X_{j}+\varepsilon_{\text {hijt }}$ 


\section{Learning from Customers}

Where $\gamma_{h i}, \alpha_{t}, X_{\mathrm{j}}$, Backlog $_{\mathrm{ij}}$ and each of the key independent variables are as previously described. Hypothesis 2 predicts that the interactions with focus (the opposite of variety) will have a negative effect on performance $\left(\theta_{2}>0\right.$, given that positive estimates indicate longer completion time). Hypothesis $4 \mathrm{~A}$ predicts that the interactions with the organization's customer experience will have a positive effect on performance $\left(\theta_{6}<\theta_{5}<0\right)$, while Hypothesis $4 \mathrm{~B}$ predicts that these interactions will have a negative effect on performance $\left(\theta_{6}>\theta_{5}>0\right)$.

\section{Results}

Table 2 contains estimates from models testing our four hypotheses. We present baseline estimates related to overall customer-specific volume in Column 1. The estimate on IndvlCustomer in Column 1 is in the expected direction and larger in magnitude than the estimate on IndvlOtherCustomer. However, this estimate is not significant at conventional levels.

With respect to Hypotheses $1 \mathrm{a}$ and $1 \mathrm{~b}$, the estimate on IndvlCustomerDomain in Column 2 is larger in absolute magnitude than any of the other three estimates, and the estimate on IndvlCustomerDomain is significantly different from each of the other three estimates at conventional levels (p-values from F-tests are each less than 0.03). This result supports Hypotheses 1a and 1b, suggesting that individual customer-domain experience is more beneficial, on average, than other types of experience. Relative to the mean level of customer-domain experience of 43.51 , an additional 1,000 cases $^{6}$ of experience yields a reduction in READTIME of approximately 13.83 seconds. This reduction in READTIME would result in approximately 54 additional cases read during a typical 40-hour work week, a $7.4 \%$ increase in the average weekly volume for a radiologist. This compares to a reduction of approximately 0.98 seconds from 1,000 additional units of domain experience, and 0.64 seconds from the same amount of other experience. Consistent with Hypotheses 1a and 1b, these findings suggest that there is substantial customer-domain specificity in learning at the level of the individual radiologist.

\footnotetext{
${ }^{6}$ Though this represents a substantial increase from the mean, it is well within the relevant range of customerdomain experience found in our data. The maximum number of reads in our data set that are customer and domain specific is 1,430. Moreover, this level of increase makes for a more meaningful comparison to other types of experience (e.g., IndvlOtherCustomerDomain) for which mean levels are much higher (e.g., 7,579).
} 


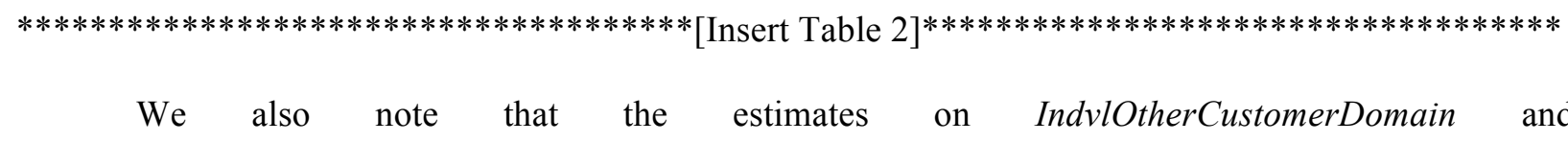

IndvlOtherCustomerOtherDomain suggest that, although increases in both measures significantly improve individual performance, domain-specific experience is more beneficial than experience with other domains and other customers (Column 2). An F-test of the difference between these two estimates is statistically significant $(\mathrm{p}<0.001)$. This result empirically supports why subspecialties in radiology are organized according to specific domains.

Columns 3 and 4 present models testing Hypothesis 3. Column 3 shows the results of the model in which OrgCustomer is entered in linear form. The estimate is negative and significant at conventional levels suggesting that productivity improves across all radiologists the more experience OutsourceCo has with a particular customer. Specifically, relative to mean levels of OrgCustomer, a customer sending an additional 1,000 cases to OutsourceCo yields a reduction in READTIME of approximately 3.67 seconds. Similarly, the estimates in Column 4 suggest that, relative to customers in OrgCustomer1, customers in OrgCustomer 2 and OrgCustomer 3 have values of READTIME that are 10.81 and 16.72 seconds faster, respectively. We note that the estimates for customers in OrgCustomer2 and OrgCustomer3 are significantly different from each other at conventional levels $(\mathrm{p}<0.001)$. These findings support the predictions of Hypothesis 3.

Columns 5 and 7 include estimates testing Hypothesis 2. Specifically, in these models IndvlCustomerFocus is interacted with our customer-specific experience variablesIndvlCustomerDomain and IndvlCustomerOtherDomain-with the IndvlCustomerDomain interaction constituting the key test of our hypothesis. In Column 5, the OrgCustomer interactions are excluded. We note that the estimates on the main effect of IndvlCustomerFocus in Columns 1, 2, 5, 6 and 7 provide consistent and significant evidence that variety is beneficial for individual performance, as higher levels of IndvlCustomerFocus indicate less variety. With respect to the interaction effects, the results in Column 5 suggest that variety has a complementary impact on the effect of customer-specific experience. In other words, the more variety in a radiologist's previous experience (lower levels of the focus variable) the 


\section{Learning from Customers}

stronger is the effect of customer-specific experience on read times. However, while this estimated effect is significant with respect to the interaction with IndvlCustomerOtherDomain, the interaction with IndvlCustomerDomain is not significant at conventional levels. Thus, the results in Column 5 do not provide strong support in favor of Hypothesis 2. We note, however, that in the fully specified model (4) in Column 7, both interaction estimates that include IndvlCustomerFocus are in the expected direction and significant at conventional levels. Nevertheless, though the magnitude and significance of the interaction with IndvlCustomerDomain in Column 7 support Hypothesis 2, the lack of a consistent finding in Column 5 suggests only partial support for Hypothesis 2 .

Finally, Columns 6 and 7 present the results for interactions between individual and organizational customer experience. In Column 6, the IndvlCustomerFocus interactions are excluded. We note that the estimates on the radiologist experience variables demonstrate the same pattern seen in Column 2, with statistically significant differences suggesting strong evidence of radiologist domain specificity across the full sample and customer-domain-specificity among customers in the first third of OrgCustomer. We also note that the estimates on IndvlCustomerOtherDomain in Columns 6 and 7 are significant at conventional levels. The estimates on the main effects of OrgCustomer2 and OrgCustomer3 in Columns 6 and 7 are similar to, though slightly lower in magnitude, than the results presented in Column 4. Collectively these findings on the main effects in Columns 6 and 7 are consistent with Hypotheses 1 and 3, suggesting that customer learning takes place at the individual (among relatively new OutsourceCo customers) and organization levels.

The key question with respect to Hypothesis 4, however, is whether individual and organizational customer experience are complements or substitutes. The estimated interactions in Columns 6 and 7 suggest a substitutive effect. Note that the estimated interactions of OrgCustomer with IndvlCustomerDomain and IndvlCustomerOtherDomain, respectively, in both columns are positive and follow a moderating pattern. Specifically, these estimates run in the opposite direction of the main effects, suggesting that the benefit of individual customer experience is diminishing with increasing organizational customer experience. In the fully specified model in Column 7 the absolute magnitude of 


\section{Learning from Customers}

the relevant OrgCustomer 3 interaction term equals 63 percent of the IndvlCustomerOtherDomain main effect and 90 percent of the IndvlCustomerDomain main effect. A similar pattern, though slightly smaller in magnitude, is observed in the interaction with OrgCustomer2. These interaction effects for IndvlCustomerDomain and IndvlCustomerOtherDomain are significant at conventional levels and support Hypothesis 4B (over Hypothesis 4A), suggesting that individual customer specificity diminishes as OutsourceCo gains more experience with a particular customer.

\subsection{Robustness}

As with other studies of this nature, our results may be sensitive to the choices we have made in constructing our variables and selecting our methods. First, as described previously, measuring READTIME required us to define radiologist shifts by estimating breakpoints based on the elapsed time between the time out of the prior read and the time out of the current read. We use 30 minutes as the breakpoint threshold for our base models but also examine the sensitivity of our results to using 20 minute and 40-minute breakpoints. These results, reported in Columns 1 and 2 of Table 3, are similar in direction, magnitude, and statistical significance to those appearing in Column 7 of Table 2. Further, test statistics comparing the various estimates in each column in Table 3 for customer specificity are consistent with those reported above for Table 2. Specifically, the main effect for IndvlCustomerDomain is greater in absolute magnitude than those for IndvlOtherCustomerDomain and IndvlOtherCustomerOtherDomain, and both of these differences are significant at the $1 \%$ level. In addition, the main effects for OrgCustomer 2 and OrgCustomer 3 are consistent in direction, magnitude and significance with the estimates in Table 2. Finally, the results in Table 3 suggest that customer specificity is diminishing in the level of OrgCustomer. Collectively, the results in Table 3 suggest that our base findings are robust to changes in how breaks between shifts are defined.

Second, our base model includes OrgCustomer entered categorically in thirds. As noted earlier, this was done in part to reduce the correlation between OrgCustomer and IndvlCustomerDomain. A second reason for this choice relates to the interpretation of interaction effects. By dividing a linear variable into categories, or levels, interpretation of its moderating influence on another linear variable is 
substantially simplified. Nevertheless, our choice to categorize OrgCustomer in thirds may seem arbitrary. Accordingly, we also examine our base model with OrgCustomer categorized in halves (above and below median) and quartiles. These results (not shown, but available from the authors) are consistent with the results from our base model and suggest that our findings are robust to how OrgCustomer is divided into discrete categories.

\section{Discussion and Conclusion}

Though many markets have traditionally been restricted by geography (Baumgardner 1988), innovations in information and communication technologies have reduced these barriers (Zuboff 1988; Autor et al. 2002). Given the ability to convert the information on a piece of paper or an image into bits (e.g., through scanning technology or digital imaging) and send those bits around the world (e.g., via the internet), the potential market size for certain service providers is increasing; offering the opportunity for greater specialization. In turn, these effects are leading to more outsourcing (Levy and Murnane 2004; Levy 2008; Malone et al. 2011) and an increase in arms-length interactions between customers and suppliers. The experience that arises from these interactions, however, remains understudied.

Our results highlight the importance of learning curves in interdependent, knowledge-based work. Further, they suggest that the established relationship between volume and performance that underpins the learning curve needs to account for the multiple dimensions of experience that can be accumulated (Lapré and Nembhard 2010; Argote and Miron-Spektor 2011). In particular, we find that both individual and organizational customer experience aid individual performance. Moreover, we find that experience across a wider variety of customers may aid the rate at which individuals learn from their own customer-specific experience. Finally, we find that individual customer specificity is moderated by the depth of the organization's experience with a customer, suggesting that individual and organizational customer experience are substitutes.

Our findings have important theoretical and managerial implications. At the individual level, we find that both customer-specific experience and variety across customers have positive effects on 


\section{Learning from Customers}

individual performance, with the magnitude of the former being significantly greater than that of the

latter. We also find that variety in experience across customers can aid the rate of learning from customer-specific experience. The caveat is that increasing variety across customers leads to a simultaneous limiting of the degree to which one can gain customer-specific experience. The question thus arises as to how one should combine the seemingly contradictory approaches of increasing customerspecific experience and increasing variety across customers served. Our findings provide insight into this issue by highlighting that customer specialization and variety may be mutually reinforcing strategies (Narayanan et al. 2009; Clark and Huckman 2012; Staats and Gino 2012). The implication is that there may be limits to the benefits of both customer-specific volume and variety across customers, suggesting the need for an optimal mix of both types of experience. Future work should build on this finding through the use of field or laboratory experiments to examine the nature of this optimal mix.

Our findings in an outsourcing context offer important insights into the study of organizational and individual learning. Prior work on organizational learning highlights the important, but largely separate roles of interorganizational (e.g., Ingram 2002) and intraorganizational learning (e.g., Argote and Ophir 2002). The shifting boundaries of firms, however, suggest the need for theory that bridges the traditional interorganizational-intraorganizational distinction. Beyond the customer-specificity of individual learning, repetitive interactions with a customer may also lead to knowledge transfer across firm boundaries that could lead to changes in organizational processes. There is a need for detailed studies to understand how such learning and knowledge transfer does (or does not) occur and whether these knowledge transactions can be structured in a way that produces performance benefits comparable to (or even exceeding) what is possible within a single firm (Nickerson and Zenger 2004). While studies such as Hansen (1999) and Szulanski (1996) examine the factors that help or hinder knowledge transfer within the firm, the shifting boundaries of firms offer the opportunity to examine both the cross-firm factors that lead to knowledge transfer and how those compare to and interact with within-firm factors.

Our findings also inform the strategic management literature concerning the microfoundations of organizational capability (Ethiraj et al. 2005; Felin and Foss 2005), where an important question is 


\section{Learning from Customers}

whether capabilities reside at the level of individuals or the organization as a whole (Staats 2012). Individuals are the actors who complete most of the work for an organization (Argote and Ingram 2000), and a large body of work highlights the key role that individual human capital plays in organizational success (Hatch and Dyer 2004; Hitt et al. 2006). Through norms, systems, and routines, however, capability may also reside at the level of the organization. This question is not simply important in the abstract. From a strategic perspective, if customer specificity resides mainly at the level of the individual, the organization may face difficulty in leveraging its human capital to build a sustainable competitive advantage (Hatch and Dyer 2004). Instead, employees may capture rents through either salary increases or moving to a competitor.

Our results, however, show that capability resides at both levels, as organizational and individual experience act as substitutes in their effects on performance. Thus although individuals certainly play a key role in successfully delivering a service-particularly early in a customer's relationship with the organization-customer capability may also be built at the level of the organization over time. Future work should examine the applicability of our framework in other contexts and seek to identify other dimensions along which experience might meaningfully vary.

Determining whether customer experience at the individual level is a complement to or substitute for the same at the organizational level also has meaningful implications for the management of outsourcing firms. Operationally, minimizing individual customer specificity is preferable because, if individual workers must be dedicated to a customer, outsourcers lose flexibility in task allocation and face lower labor utilization. Dedicating particular staff to a small number of customers also might limit variety in the work of those individuals, which could lead to employee dissatisfaction and eventual turnover (Fried and Ferris 1987). Our findings suggest that, for new customers, an outsourcing firm may wish to keep individual providers relatively more focused on serving a specific customer. As organizational experience accrues with a specific customer, however, such dedication becomes less critical.

\subsection{Limitations and Future Research}




\section{Learning from Customers}

Despite the robustness of our results, our study faces several limitations. First, we cannot assume that our findings generalize to other settings. We note, however, that our results are likely relevant for a wide range of settings that are characterized by an individual performing a varied set of related and roughly repetitive activities for a range of customers. Similar contexts might include settings in manufacturing or professional services (e.g., software development, legal, or consulting services).

Second, despite our efforts to control for time-invariant factors such as individual talent and the "match" between individual providers and customers, our results may still be subject to concerns of bias due to remaining sources of endogeneity. Nonetheless, we reiterate that-within pre-defined bounds based on the range of technologies for which an individual has been trained and the hospitals at which an individual is able to practice - the assignment of individual cases does not depend on the unobserved characteristics of cases, customers, or individual radiologists.

Third, the realities of our data require us to analyze individual and organizational experience differently. For individual experience, we are able to test for learning from customer experience, as well as customer specificity. We examine the latter concept by including all types of experience for each radiologist in the model and testing whether customer-domain experience has a greater effect on learning than other types of experience. We find that this is the case. For organizational experience, our data only allow us to test whether learning occurs at the organizational level. Including a variable that captures all other OutsourceCo experience-which would be required to test for customer specificity at the organizational level — is not feasible as this variable is highly correlated with other experience variables in the model and would be akin to adding a variable for calendar time, which is already in our models. Future work should thus examine whether customer specificity also occurs at the organizational level. In addition, future work should explore the effect that other employees' experience with different customers has on an individual's performance with a focal customer.

Fourth, though our study provides accurate measurement of the number of interactions between an individual radiologist and a customer, we do not observe what takes place during each interaction. Future work should seek to examine how these interactions can be structured more effectively to improve 


\section{Learning from Customers}

coordination. For example, Huckman and Pisano (2006) find that an individual's experience with the specific assets of his or her employer is important to improving performance (i.e., experience is firmspecific). They suggest that one source of this firm-specificity may be the familiarity that emerges between workers within a given firm (Huckman et al. 2009; Staats 2012). Research that examines both how a radiologist interacts with a customer, as well as how radiologists at a firm interact with each other could provide valuable additional insight.

Finally, our results only measure performance in terms of speed rather than clinical outcome or some other measure of performance quality. This is due to the fact that our data reveal that only $0.3 \%$ of our cases are characterized by a quality "discrepancy" and that many of these discrepancies are simply the result of a need for clarification rather than deficient performance. This low level of quality problems is beneficial not only for patients but also for our empirical identification strategy. Specifically, to the extent that quality is almost uniformly acceptable across all providers in our sample, we are able to use read time as a measure of performance effectiveness. Future work should explore the effect of customer experience on quality. For example, outsourcing may lead to unexpected quality challenges, in some settings, as complex information must often be transmitted and translated across the boundaries of multiple organizations. While we expect hat our results would hold with quality as a dependent variable, it is an important topic for further study.

Even with these potential limitations, our results have significant implications for both the suppliers and users of outsourced services. For firms that provide outsourced services, we emphasize that the observed nature of learning implies that staffing decisions should account for multiple dimensions of experience, such as prior experience with a specific customer, that are often overlooked in settings where activities are assumed to be "commoditized". For firms that use outsourced services, our findings suggest that performance may be improved by efforts to leverage customer experience, particularly early in their relationship with an outsourcing firm. Such firms, however, should realize that just as such individual specificity improves performance; it also increases the potential for an outsourcer to "hold up" a customer 
that becomes reliant on its expertise. Overall, our findings point to the need for future research that examines the long-term costs and benefits of leveraging the specific nature of experience.

\subsection{Conclusion}

Our study follows calls in the academy to go "behind" the learning curve (Adler and Clark 1991; Argote 1999; Lapré 2011). In particular, we are able to examine how experience accumulation across multiple-levels in the firm affects individual performance (Hackman 2003) and, in so doing, makes six contributions. First, we study a type of experience - customer experience - that is both underexamined and of growing importance. Our setting not only provides us with detailed data to examine multiple interactions between providers and customers but also provides the "clean" assignment of tasks to individuals required for us to draw causal inferences from our results. Second, we find evidence of customer specificity in individual performance. Further, our results also support the concept of domain specificity in healthcare. Given that not all experience has an equal impact on future performance, it is important to understand the incremental impact of these various types of experience on performance. Our results show that specialization in customer experience offers performance benefits for individuals. Future work should not only examine where experience comes from (e.g., customer) but also the heterogeneity of the knowledge gained within a particular type of experience (e.g., heterogeneity within a given customer, Haunschild \& Sullivan 2002).

Third, we find that organizational customer experience leads to improved individual performance. Because the work of an organization is conducted by individuals, it is important to identify the distinct impact of customer experience at each of these two levels. Our result at the organizationallevel also offers insight for research on strategic alliances. Prior work on learning in strategic alliances emphasizes the need to learn about a partner to build a successful alliance (Doz 1996; Arino and Torre 1998) and also highlights the possibility of knowledge transfer and learning from the alliance partner (see Inkpen and Tsang 2007, for a literature review). Though learning may be possible, it often requires significant effort on the part of both parties (Teece 1977; Inkpen and Pien 2006). Further, learning from 
other parties requires that the parties internalize their experience together to convert it into know-how (Simonin 1997). As noted by Inkpen and Tsang (2007, p. 504), the above stream of research has not directly examined repeated interactions between partners - the focus of our study.

Fourth, we find that increasing the variety of customer experience at the individual level may be related to faster customer-specific learning. Thus, we find that specialization and variety may be optimally used as mutually reinforcing rather than mutually exclusive strategies (Narayanan et al. 2009; Clark and Huckman 2012; Staats and Gino 2012; KC and Staats 2012). Fifth, our work speaks to a recent suggestion that “...[u]nderstanding when different types of experience are complements or substitutes for one other is an important topic for future research (Argote and Miron-Spektor, 2011, p. 1127)." In examining customer experience, we find that individual and organizational customer experience are substitutes in terms of their effects on individual performance - greater organizational experience with a given customer reduces the importance of customer experience at the individual level. We recognize, however, that various circumstances (e.g., technology, work practices, structure, culture) might moderate the relationship between individual and organizational experience. Future work should seek to understand these factors and how they lead to either a complementary or substitutive relationship.

Finally, our work offers guidance for both providers and customers in service settings. Namely, each should be cognizant of the detailed experience profiles of the individuals completing the work. Increasingly, managers looking to improve performance must focus on the portfolio of experiences gained not only by their employees, but also by their service providers. Our hope is that unpacking experience along these lines will help build more accurate theory and generate additional insights for managers. 


\section{References}

Adler, P. S. and K. B. Clark (1991). "Behind the learning curve: A sketch of the learning process." Management Sci. 37(3): 267-281.

Argote, L. (1982). "Input uncertainty and organizational coordination in hospital emergency units." Administrative Sci. Q. 27(3): 420-434.

Argote, L. (1999). Organizational Learning: Creating, Retaining, and Transferring Knowledge. Boston, Kluwer Academic.

Argote, L., S. L. Beckman and D. Epple (1990). "The persistence and transfer of learning in industrial settings." Management Sci. 36(2): 140-154.

Argote, L. and P. Ingram (2000). "Knowledge transfer: A basis for competitive advantage in firms." Organ. Behav. Human Decision Processes 82(1): 150-169.

Argote, L. and E. Miron-Spektor (2011). "Organizational learning: From experience to knowledge." Organ. Sci. 22(5): 1123-1137.

Argote, L. and R. Ophir (2002). Intraorganizational learning. The Blackwell Companion to Organizations. J. Baum. New York, Blackwell.

Arino, A. and J. d. 1. Torre (1998). "Learning from failure: Towards an evolutionary model of collaborative ventures." Organ. Sci. 9(3): 306-325.

Arora, A., V. S. Arunachalam, J. Asundi and R. Fernandes (2001). "The Indian software services industry." Research Policy 30(8): 1267-1287.

Arrow, K. J. (1974). The Limits of Organization. New York, W.W. Norton \& Co.

Autor, D. H., F. Levy and R. J. Murnane (2002). "Upstairs, downstairs: Computers and skills on two floors of a large bank." Industrial and Labor Relations Review 55(3): 432-447.

Bandura, A. (1977). "Self-efficacy: Toward a unifying theory of behavioral change." Psych. Rev. 84(2): 191-215.

Baumgardner, J. R. (1988). "Physicians' services and the division of labor across local markets." Journal of Political Economy 96(5): 948-982.

Boh, W. F., S. A. Slaughter and J. A. Espinosa (2007). "Learning from experience in software development: A multilevel analysis." Management Sci. 53(8): 1315-1331.

Bohn, R. E. (2005). "From art to science in manufacturing: The evolution of technological knowledge." Foundations and Trends in Technology, Information and Operations Management 1(2): 129-212.

Bohn, R. E. and M. A. Lapré (2011). Accelerated learning by experimentation. Learning Curves: Theory, Models, and Applications. M. Y. Jaber. Boca Raton, FL, CRC Press, Taylor and Francis: 191209.

Boone, T., R. Ganeshan and R. L. Hicks (2008). "Learning and knowledge depreciation in professional services." Management Sci. 54(7): 1231-1236.

Brunner, D. J. (2009). "Computer-assisted organizing: Implications of information technology for firm strategy and business scalability." Unpublished doctoral dissertation: Boston, MA.

Clark, J. R. and R. S. Huckman (2012). "Broadening focus: Spillovers and the benefits of specialization in the hospital industry." Management Sci. 58(4): 708-722.

Cohen, W. M. and D. A. Levinthal (1990). "Absorptive capacity: A new perspective on learning and innovation." Administrative Sci. Q. 35(1): 128-152.

Dosi, G., R. R. Nelson and S. G. Winter (2000). The Nature and Dynamics of Organizational Capabilities. London, Oxford University Press.

Doz, Y. L. (1996). "The evolution of cooperation in strategic alliances: Initial conditions or learning processes?" Strategic Management J. 17(Evolutionary Perspectives on Strategy): 55-83.

Ellis, H. C. (1965). The transfer of learning. New York, Macmillan.

Ethiraj, S. K., P. Kale, M. S. Krishnan and J. V. Singh (2005). "Where do capabilities come from and how do they matter? A study in the software services industry." Strategic Management J. 26(1): 25-45. 
Felin, T. and N. J. Foss (2005). "Strategic organization: A field in search of micro-foundations." Strategic Organization 3(4): 441-455.

Fleming, L. and O. Sorenson (2004). "Science as a map in technological search." Strategic Management J. 25(8-9): 909-928.

Fried, Y. and G. R. Ferris (1987). "The validity of the job characteristics model: A review and metaanalysis." Pers. Psych. 40(2): 287-322.

Gino, F., L. Argote, E. Miron-Spektor and G. Todorova (2010). "First, get your feet wet: The effects of learning from direct and indirect experience on team creativity." Organ. Behav. Human Decision Processes 111(2): 102-115.

Hackman, J. R. (2003). "Learning more by crossing levels: Evidence from airplanes, hospitals, and orchestras." J. of Organ. Behav. 24: 1-18.

Hansen, M. T. (1999). "The Search-Transfer Problem: The role of weak ties in sharing knowledge across organization subunits." Administrative Sci. Q. 44(1): 82-111.

Hargadon, A. and R. I. Sutton (1997). "Technology brokering and innovation in a product development firm." Administrative Sci. Q. 42(4): 716-749.

Hatch, N. W. and J. H. Dyer (2004). "Human capital and learning as a source of sustainable competitive advantage." Strategic Management J. 25(12): 1155-1178.

Haunschild, P. R. and B. N. Sullivan (2002). "Learning from complexity: Effects of prior accidents and incidents on airlines' learning." Administrative Sci. Q. 47(4): 609.

Hayes, R. H., G. P. Pisano, D. M. Upton and S. C. Wheelwright (2005). Operations, strategy and technology: pursuing the competitive edge. Hoboken, NJ, Wiley.

Hitt, M. A., L. Bierman, K. Uhlenbruck and K. Shimizu (2006). "The importance of resources in the internationalization of professional service firms: The good, the bad, and the ugly." Academy Manage. J. 49(6): 1137-1157.

Hofmann, D. A., Z. Lei and A. M. Grant (2009). "Seeking help in the shadow of doubt: The sensemaking processes underlying how nurses decide whom to ask for advice." J. Appl. Psych. 94(5): 12611274.

Huckman, R. S. and G. P. Pisano (2006). "The firm specificity of individual performance: Evidence from cardiac surgery." Management Sci. 52(4): 473-488.

Huckman, R. S. and B. R. Staats (2011). "Fluid tasks and fluid teams: The impact of diversity in experience and team familiarity on team performance." Manufacturing Service Oper. Management 13(3): 310-328.

Huckman, R. S., B. R. Staats and D. M. Upton (2009). "Team familiarity, role experience, and performance: Evidence from Indian software services." Management Sci. 55(1): 85-100.

Ingram, P. (2002). Interorganizational learning. The Blackwell Companion to Organizations. J. Baum. Oxford, Blackwell Business: 181-207.

Inkpen, A. C. and W. Pien (2006). "An examination of collaboration and knowledge transfer: ChinaSingapore Suzhou Industrial Park." Journal of Management Studies 43(4): 779-811.

Inkpen, A. C. and E. W. K. Tsang (2007). "Learning and strategic alliances." Academy of Management Annals 1(1): 479-511.

Kang, K. and J. Hahn (2009). "Learning and forgetting curves in software development: Does type of knowledge matter?" ICIS 2009 Proceedings Paper 194.

KC, D. and B. R. Staats (Forthcoming). "Accumulating a portfolio of experience: The effect of focal and related experience on surgeon performance." Manufacturing Service Oper. Management.

Kim, D. H. (1993). "The link between individual learning and organizational learning." Sloan Management Review 35(1): 37-50.

Ko, D.-G., L. J. Kirsch and W. R. King (2005). "Antecedents of knowledge transfer from consultants to clients in enterprise system implementations." MIS Quarterly 29(1): 59-85.

Lane, P. J. and M. Lubatkin (1998). "Relative absorptive capacity and interorganizational learning." Strategic Management J. 19(5): 461-477. 
Lapré, M. A. (2011). Inside the learning curve: Opening the black box of the learning curve. Learning Curves: Theory, Models, and Applications. M. Y. Jaber. Boca Raton, FL, CRC Press, Taylor and Francis: 23-35.

Lapré, M. A., A. S. Mukherjee and L. N. V. Wassenhove (2000). "Behind the learning curve: Linking learning activities to waste reduction." Management Sci. 46(5): 597-611.

Lapré, M. A. and I. M. Nembhard (2010). "Inside the organizational learning curve: Understanding the organizational learning process." Foundations and Trends in Technology, Information and Operations Management 4(1): 1-103.

Lapré, M. A. and N. Tsikriktsis (2006). "Organizational learning curves for customer dissatisfaction: Heterogeneity across airlines." Management Sci. 52(3): 352-366.

Larsson, R. and D. E. Bowen (1989). "Organization and customer: Managing design and coordination of services." The Academy of Management Review 14(2): 213-233.

Lee, F. (1997). "When the going gets tough, do the tough ask for help? Help seeking and power motivation in organizations." Organ. Behav. Human Decision Processes 72(3): 336-363.

Levinthal, D. A. and J. G. March (1993). "The myopia of learning." Strategic Management J. 14: 95-112.

Levy, F. (2008). "Computers and the supply of radiology services: Anatomy of a disruptive technology." Journal of the American College of Radiology 5(10): 1067-1072.

Levy, F. and A. Goelman (2005). Offshoring and radiology. Brookings Trade Forum: Offshoring White Collar Work. L. Brainard and S. M. Collins.

Levy, F. and R. J. Murnane (2004). The New Division of Labor: How Computers are Creating the Next Job Market. Princeton, N.J., Princeton University Press.

Lewis, R., J. Sunshine and M. Bhargavan (2009). "Radiology Practices Use of External Off-Hours Teleradiology Services in 2007 and Changes since 2003." American Journal of Roentgenology 193: 1333-1339.

Lubatkin, M., J. Florin and P. Lane (2001). "Learning together and apart: A model of reciprocal interfirm learning." Human Relations 54(10): 1353-1382.

Malone, T. W., R. J. Laubacher and T. Johns (2011). "The age of hyperspecialization." Harvard Business Rev. 89(7/8): 56-65.

March, J. G. and H. A. Simon (1993). Organizations. Cambridge, MA, Blackwell.

McEvily, B., V. Perrone and A. Zaheer (2003). "Trust as an organizing principle." Organ. Sci. 14(1): 91103.

Metiu, A. (2006). "Owning the code: Status closure in distributed groups." Organ. Sci. 17(4): 418-435.

Mishina, K. (1999). Learning by new experiences: Revisiting the flying fortress learning curve. Learning by Doing in Markets, Firms, and Countries. N. R. Lamoreaux, D. M. G. Raff and P. Temin. Chicago, University of Chicago Press: 145-179.

Monsell, S. (2003). "Task switching." Trends in cognitive sciences 7(3): 134-140.

Mowery, D. C. and J. E. Oxley (1995). "Inward technology transfer and competitiveness: The role of national innovation systems." Cambridge Journal of Economics 19(1): 67-93.

Mowery, D. C., J. E. Oxley and B. S. Silverman (2002). The two faces of partner-specific absorptive capacity: Learning and cospecialization in strategic alliances. Cooperative Strategies and Alliances. F. J. Contractor and P. Lorange. Amsterdam, Pergamon: 291-320.

Narayanan, S., S. Balasubramanian and J. M. Swaminathan (2009). "A matter of balance: Specialization, task variety, and individual learning in a software maintenance environment." Management Sci. 55(11): 1861-1876.

Nelson, R. R. and S. G. Winter (1982). An Evolutionary Theory of Economic Change. Cambridge, MA, Belknap Press.

Newell, A. and P. Rosenbloom (1981). Mechanisms of skill acquisition \& the power law of practice. Cognitive Skills \& Their Acquisition. J. Anderson. Hillsdale, NJ, Erlbaum: 1-55.

Nickerson, J. A. and T. R. Zenger (2004). "A knowledge-based theory of the firm: The problem-solving perspective." Organ. Sci. 15(6): 617-632.

Nonaka, I. (1994). "A dynamic theory of organizational knowledge creation." Organ. Sci. 5(1): 14-37. 
Nonaka, I. and H. Takeuchi (1995). The Knowledge-Creating Company: How Japanese Companies Create the Dynamics of Innovation. New York, Oxford University Press.

Piaget, J. (1963). The Psychology of Intelligence. New York, Routledge.

Pisano, G. P., R. M. J. Bohmer and A. C. Edmondson (2001). "Organizational differences in rates of learning: Evidence from the adoption of minimally invasive cardiac surgery." Management Sci. 47(6): 752-768.

Reagans, R., L. Argote and D. Brooks (2005). "Individual experience and experience working together: Predicting learning rates from knowing who knows what and knowing how to work together." Management Sci. 51(6): 869-881.

Schilling, M. A., P. Vidal, R. E. Ployhart and A. Marangoni (2003). "Learning by doing something else: Variation, relatedness, and the learning curve." Management Sci. 49(1): 39-56.

Schwab, A. (2007). "Incremental organizational learning from multilevel information sources: evidence for cross-level interactions." Organ. Sci. 18(2): 233-251.

Simonin, B. L. (1997). "The importance of collaborative know-how: An empirical test of the learning organization." Academy Manage. J. 40(5): 1150-1174.

Skinner, W. (1974). "The focused factory." Harvard Business Rev. 52(3): 113-121.

Smith, A. (1776). An Inquiry into the Nature and Causes of the Wealth of Nations, Edwin Cannan, ed. Library of Economics and Liberty. Retrieved March 9, 2011: http://www.econlib.org/library/Smith/smWN1.html.

Staats, B. R. (2012). "Unpacking team familiarity: The effect of geographic location and hierarchical role." Production and Operations Management. 21(3): 619-635.

Staats, B. R., D. J. Brunner and D. M. Upton (2011). "Lean principles, learning, and knowledge work: Evidence from a software services provider." J. of Operations Management 29(5): 376-390.

Staats, B. R. and F. Gino (2012). "Specialization and variety in repetitive tasks: Evidence from a Japanese bank." Management Sci. 58(6): 1141-1159.

Steinbrook, R. (2007). "The age of teleradiology." N. Engl. J. Med. 357(1): 5-7.

Studdert, D. M., M. M. Mello, W. M. Sage, C. M. DesRoches, J. Peugh, K. Zapert and T. A. Brennan (2005). "Defensive medicine among high-risk specialist physicians in a volatile malpractice environment." Journal of the American Medical Association 293(21): 2609-2617.

Szulanski, G. (1996). "Exploring internal stickiness: Impediments to the transfer of best practice within the firm." Strategic Management J. 17(Special Issue: Knowledge and the Firm): 27-43.

Szulanski, G. (2000). "The process of knowledge transfer: A diachronic analysis of stickiness." Organ. Behav. Human Decision Processes 82(1): 9-27.

Teece, D. J. (1977). "Technology transfer by multinational firms: The resource cost of transferring technological know-how." The Economic Journal 87(346): 242-261.

Thompson, J. D. (1967). Organizations in Action. New Brunswick, NJ, Transaction Publishers.

Uzzi, B. (1997). "Social structure and competition in interfirm networks: The paradox of embeddedness." Administrative Sci. Q. 42(1): 35-67.

Wachter, R. M. (2006). "International teleradiology." N. Engl. J. Med. 354(7): 662-663.

Walsh, J. P. and G. R. Ungson (1991). "Organizational memory." Acad. Management Rev. 16(1): 57-91.

Weber, R. A. and C. F. Camerer (2003). "Cultural conflict and merger failure." Management Sci. 49(4): 400-415.

Weiss, H. M., K. Suckow and T. L. Rakestraw Jr (1999). "Influence of modeling on self-set goals: Direct and mediated effects." Human Performance 12(2): 89.

Yelle, L. E. (1979). "The learning curve: Historical review and comprehensive story." Decision Sci. 10(2): 302-328.

Zahra, S. A. and G. George (2002). "Absorptive capacity: A review, reconceptualization, and extension." Acad. Management Rev. 27(2): 185-203.

Zuboff, S. (1988). In the age of the smart machine: The future of work and power. New York, Basic Books. 


\section{Figures \& Tables}

Figure 1. Segmenting individual experience by customer and domain relative to the current case.

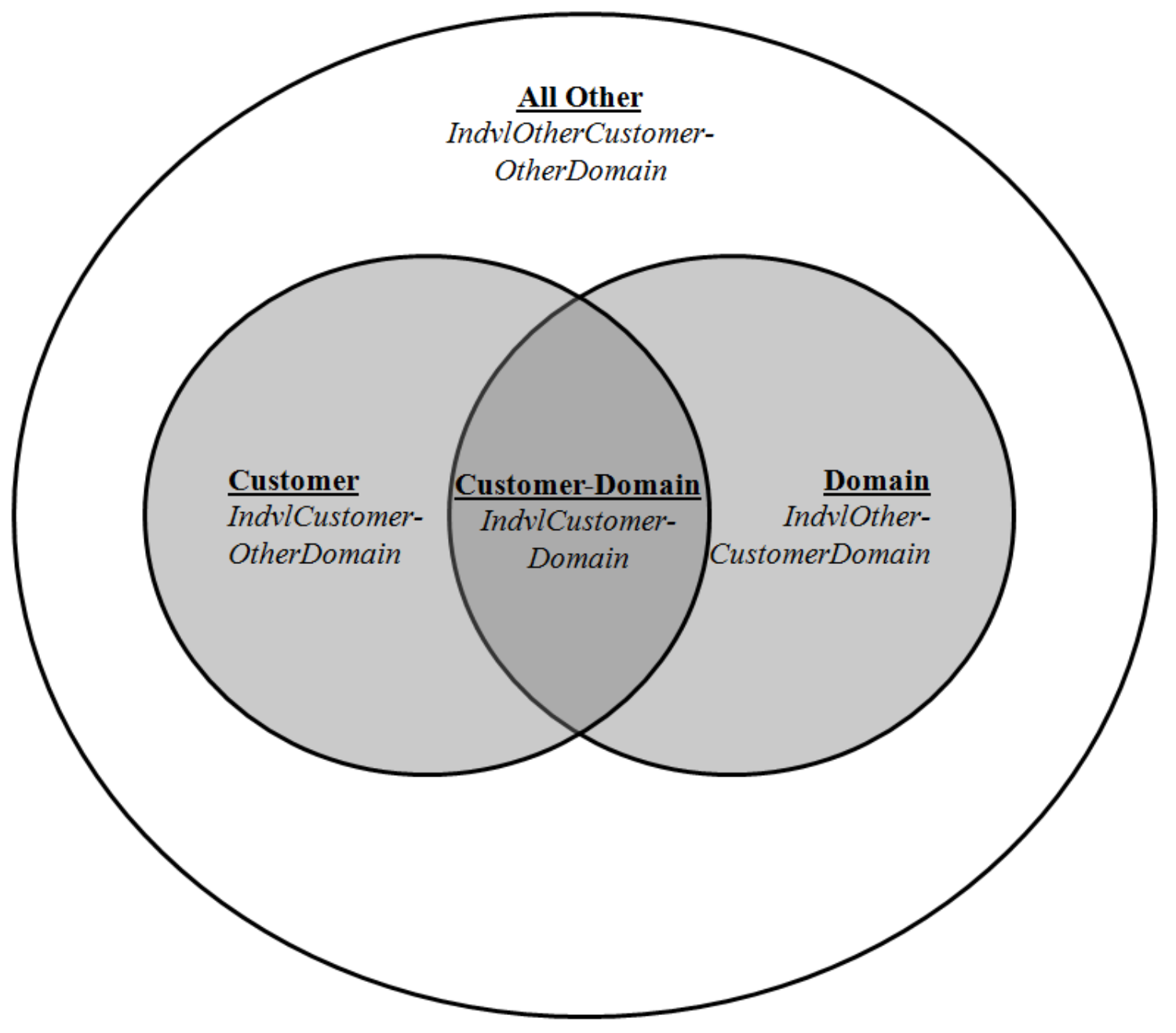


Learning from Customers

Table 1a. Summary statistics for key variables.

\begin{tabular}{|c|c|c|c|c|c|c|c|c|c|}
\hline Variable & Mean & Std. Dev. & (1) & (2) & (3) & (4) & (5) & (6) & (7) \\
\hline (1) READTIME & 4.99 & 8.90 & & & & & & & \\
\hline (2) IndvlCustomerDomain & 43.51 & 71.75 & -0.058 & & & & & & \\
\hline (3) IndvICustomerOtherDomain & 106.42 & 155.21 & -0.076 & 0.650 & & & & & \\
\hline (4) IndvlOtherCustomerDomain & $7,579.36$ & $8,034.62$ & -0.112 & 0.486 & 0.228 & & & & \\
\hline (5) IndvlOtherCustomerOtherDomain & $20,295.17$ & $17,646.61$ & -0.147 & 0.262 & 0.453 & 0.569 & & & \\
\hline (6) IndviCustomerFocus & 0.009 & 0.012 & 0.106 & -0.086 & -0.096 & -0.221 & -0.270 & & \\
\hline (7) OrgCustomer & 829.61 & $1,075.47$ & -0.013 & 0.638 & 0.340 & 0.367 & 0.111 & -0.115 & \\
\hline (8) Backlog & 4.79 & 3.86 & -0.130 & 0.091 & 0.111 & 0.203 & 0.261 & -0.109 & 0.037 \\
\hline
\end{tabular}

Table 1b. Distribution of images by domain and technology

\begin{tabular}{lr}
\hline Variable & Frequency \\
\hline Domains & \\
Abdomen & $5.5 \%$ \\
Body & $37.8 \%$ \\
Brain & $32.3 \%$ \\
Breast & $0.0 \%$ \\
Cardiovascular & $0.2 \%$ \\
Chest & $12.6 \%$ \\
Gl/GU & $1.7 \%$ \\
Head and Neck & $2.4 \%$ \\
Musculoskeletal & $1.3 \%$ \\
Obstetrics & $2.5 \%$ \\
Spine & $0.0 \%$ \\
Other & $3.6 \%$ \\
Technologies & \\
Computed Tomography (CT) & \\
Magnetic Resonance (MR) & $84.5 \%$ \\
Nuclear Medicine (NM) & $0.9 \%$ \\
Ultrasound (US) & $1.0 \%$ \\
X-Ray (XR) & $10.0 \%$ \\
\hline
\end{tabular}




\section{Learning from Customers}

Table 2. Regressions testing the effect of cumulative customer experience.

\begin{tabular}{|c|c|c|c|c|c|c|c|}
\hline VARIABLES & $\begin{array}{c}\text { (1) } \\
\text { Ln(READTIME) }\end{array}$ & $\begin{array}{c}\text { (2) } \\
\text { Ln(READTIME) }\end{array}$ & $\begin{array}{c}\text { (3) } \\
\text { Ln(READTIME) }\end{array}$ & $\begin{array}{c}\text { (4) } \\
\text { Ln(READTIME) }\end{array}$ & $\begin{array}{c}\text { (5) } \\
\text { Ln(READTIME) }\end{array}$ & $\begin{array}{c}(6) \\
\text { Ln(READTIME) }\end{array}$ & $\begin{array}{c}\text { (7) } \\
\text { Ln(READTIME) }\end{array}$ \\
\hline IndvICustomer (000's) & $\begin{array}{l}-0.0222 \\
(0.0162)\end{array}$ & & & & & & \\
\hline IndvlOtherCustomer (000's) & $\begin{array}{c}-0.0036 * * * \\
(0.0001)\end{array}$ & & & & & & \\
\hline IndvICustomerDomain (000's) & & $\begin{array}{c}-0.0717^{* *} \\
(0.0283)\end{array}$ & & & $\begin{array}{l}-0.0818^{*} \\
(0.0470)\end{array}$ & $\begin{array}{c}-1.750 * * * \\
(0.413)\end{array}$ & $\begin{array}{c}-2.200 * * * \\
(0.2520)\end{array}$ \\
\hline IndvICustomerOtherDomain (000's) & & $\begin{array}{l}-0.0045 \\
(0.0178)\end{array}$ & & & $\begin{array}{l}-0.0384 * \\
(0.0224)\end{array}$ & $\begin{array}{c}-0.0508^{* *} \\
(0.0228)\end{array}$ & $\begin{array}{c}-0.1020 * * * \\
(0.0252)\end{array}$ \\
\hline IndvlOtherCustomerDomain (000's) & & $\begin{array}{c}-0.0049 * * * \\
(0.0002)\end{array}$ & & & $\begin{array}{c}-0.0045^{* * *} \\
(0.0002)\end{array}$ & $\begin{array}{c}-0.0045^{* * *} \\
(0.0002)\end{array}$ & $\begin{array}{c}-0.0043 * * * \\
(0.0002)\end{array}$ \\
\hline IndvlOtherCustomerOtherDomain (000's) & & $\begin{array}{c}-0.0032 * * * \\
(0.0001)\end{array}$ & & & $\begin{array}{c}-0.0030 * * * \\
(0.0001)\end{array}$ & $\begin{array}{c}-0.0030 * * * \\
(0.0001)\end{array}$ & $\begin{array}{c}-0.0028 * * * \\
(0.0001)\end{array}$ \\
\hline IndviCustomerFocus & $\begin{array}{c}3.153^{* * *} \\
(0.186)\end{array}$ & $\begin{array}{c}3.152^{* * *} \\
(0.186)\end{array}$ & & & $\begin{array}{c}3.126 * * * \\
(0.185)\end{array}$ & $\begin{array}{c}2.990 * * * \\
(0.178)\end{array}$ & $\begin{array}{c}3.005^{* * *} \\
(0.181)\end{array}$ \\
\hline OrgCustomer (000's) & & & $\begin{array}{c}-0.0161 * * * \\
(0.0017)\end{array}$ & & & & \\
\hline OrgCustomer2 & & & & $\begin{array}{c}-0.0457 * * * \\
(0.0023)\end{array}$ & $\begin{array}{c}-0.0240 * * * \\
(0.00220)\end{array}$ & $\begin{array}{c}-0.0286 * * * \\
(0.0037)\end{array}$ & $\begin{array}{c}-0.0309 * * * \\
(0.00321)\end{array}$ \\
\hline OrgCustomer3 & & & & $\begin{array}{c}-0.0716 * * * \\
(0.0031)\end{array}$ & $\begin{array}{c}-0.0245^{* * *} \\
(0.00331)\end{array}$ & $\begin{array}{c}-0.0485 * * * \\
(0.0056)\end{array}$ & $\begin{array}{c}-0.0545 * * * \\
(0.00410)\end{array}$ \\
\hline $\begin{array}{l}\text { IndvlCustomerDomain x } \\
\text { IndvICustomerFocus }\end{array}$ & & & & & $\begin{array}{r}1.5130 \\
(5.9150)\end{array}$ & & $\begin{array}{c}17.200 * * * \\
(5.160)\end{array}$ \\
\hline $\begin{array}{l}\text { IndvICustomerOtherDomain } \mathrm{x} \\
\text { Indvl Customer Focus }\end{array}$ & & & & & $\begin{array}{l}4.617^{* *} \\
(1.950)\end{array}$ & & $\begin{array}{c}6.720 * * * \\
(1.750)\end{array}$ \\
\hline $\begin{array}{l}\text { IndvlCustomerDomain } \mathrm{x} \\
\text { Org Customer2 }\end{array}$ & & & & & & $\begin{array}{c}1.160 * * * \\
(0.355)\end{array}$ & $\begin{array}{c}1.380 * * * \\
(0.246)\end{array}$ \\
\hline $\begin{array}{l}\text { IndviCustomerDomain } \mathrm{x} \\
\text { Org Customer3 }\end{array}$ & & & & & & $\begin{array}{c}1.640 * * * \\
(0.403)\end{array}$ & $\begin{array}{c}1.970 * * * \\
(0.250)\end{array}$ \\
\hline $\begin{array}{l}\text { IndvlCustomerOtherDomain } \mathrm{x} \\
\text { OrgCustomer2 }\end{array}$ & & & & & & $\begin{array}{c}0.0500 * * * \\
(0.0142)\end{array}$ & $\begin{array}{c}0.0582 * * * \\
(0.0139)\end{array}$ \\
\hline $\begin{array}{l}\text { IndvICustomerOtherDomain } \mathrm{x} \\
\text { OrgCustomer3 }\end{array}$ & & & & & & $\begin{array}{c}0.0562 * * * \\
(0.0179)\end{array}$ & $\begin{array}{c}0.0638 * * * \\
(0.01 .79)\end{array}$ \\
\hline Backlog & $\begin{array}{c}-0.0246 * * * \\
(0.0002)\end{array}$ & $\begin{array}{c}-0.0246 * * * \\
(0.0002)\end{array}$ & $\begin{array}{c}-0.0254 * * * \\
(0.0002)\end{array}$ & $\begin{array}{c}-0.0255^{* * *} \\
(0.0002)\end{array}$ & $\begin{array}{c}-0.0246 * * * \\
(0.0002)\end{array}$ & $\begin{array}{c}-0.0247 * * * \\
(0.0002)\end{array}$ & $\begin{array}{c}-0.0247^{* * *} \\
(0.0002)\end{array}$ \\
\hline Observations & $2,766,209$ & $2,766,209$ & $2,766,209$ & $2,766,209$ & $2,766,209$ & $2,766,209$ & $2,766,209$ \\
\hline Customer-radiologist Pairs & 44,159 & 44,159 & 44,159 & 44,159 & 44,159 & 44,159 & 44,159 \\
\hline R-squared & 0.235 & 0.235 & 0.234 & 0.234 & 0.235 & 0.236 & 0.236 \\
\hline
\end{tabular}

Robust standard errors in parentheses are clustered by customer-radiologist pairs

Model includes a constant term and covariates not reported

*** $p<0.01, * * p<0.05, * p<0.1$ 
Table 3. Regressions with alternative radiologist "break" windows.

\begin{tabular}{|c|c|c|}
\hline VARIABLES & $\begin{array}{c}(1) \\
\text { Ln(READTIME) } \\
20 \text { min. window }\end{array}$ & $\begin{array}{c}\text { (2) } \\
\text { Ln(READTIME) } \\
40 \text { min. window }\end{array}$ \\
\hline IndvICustomerDomain (000’s) & $\begin{array}{c}-2.530 * * * \\
(0.301)\end{array}$ & $\begin{array}{c}-2.450 * * * \\
(0.312)\end{array}$ \\
\hline Indvl CustomerOtherDomain (000's) & $\begin{array}{c}-0.111^{* * *} \\
(0.0350)\end{array}$ & $\begin{array}{c}-0.103 * * * \\
(0.0348)\end{array}$ \\
\hline IndvlOtherCustomerDomain (000's) & $\begin{array}{c}-0.0056^{* * *} \\
(0.0003)\end{array}$ & $\begin{array}{c}-0.0055^{* * *} \\
(0.0003)\end{array}$ \\
\hline IndvlOtherCustomerOtherDomain (000's) & $\begin{array}{c}-0.0037 * * * \\
(0.0002)\end{array}$ & $\begin{array}{c}-0.0038 * * * \\
(0.0002)\end{array}$ \\
\hline IndvlCustomerFocus & $\begin{array}{c}3.415 * * * \\
(0.215)\end{array}$ & $\begin{array}{c}3.473 * * * \\
(0.218)\end{array}$ \\
\hline OrgCustomer2 & $\begin{array}{c}-0.0387^{* * *} \\
(0.00424)\end{array}$ & $\begin{array}{c}-0.0356 * * * \\
(0.00430)\end{array}$ \\
\hline OrgCustomer3 & $\begin{array}{c}-0.0670 * * * \\
(0.00553)\end{array}$ & $\begin{array}{c}-0.0626 * * * \\
(0.00557)\end{array}$ \\
\hline IndvlCustomerDomain $\mathrm{x}$ IndvlCustomerFocus & $\begin{array}{l}12.90^{* *} \\
(5.530)\end{array}$ & $\begin{array}{c}14.50 * * * \\
(5.550)\end{array}$ \\
\hline IndvlCustomerOtherDomain $\mathrm{x}$ IndvlCustomerFocus & $\begin{array}{c}7.270 * * * \\
(2.180)\end{array}$ & $\begin{array}{c}6.850 * * * \\
(2.110)\end{array}$ \\
\hline IndvlCustomerDomain x OrgCustomer2 & $\begin{array}{c}1.550 * * * \\
(0.283)\end{array}$ & $\begin{array}{c}1.460 * * * \\
(0.296)\end{array}$ \\
\hline IndvlCustomerDomain x OrgCustomer3 & $\begin{array}{c}2.340 * * * \\
(0.291)\end{array}$ & $\begin{array}{c}2.260 * * * \\
(0.303)\end{array}$ \\
\hline IndvlCustomerOtherDomain x OrgCustomer2 & $\begin{array}{c}0.0890 * * * \\
(0.0209)\end{array}$ & $\begin{array}{c}0.0844 * * * \\
(0.0209)\end{array}$ \\
\hline IndvlCustomerOtherDomain x OrgCustomer3 & $\begin{array}{c}0.0675^{* * *} \\
(0.0234)\end{array}$ & $\begin{array}{c}0.0575 * * \\
(0.0232)\end{array}$ \\
\hline Backlog & $\begin{array}{c}-0.0384 * * * \\
(0.0003)\end{array}$ & $\begin{array}{c}-0.0392 * * * \\
(0.0003)\end{array}$ \\
\hline Observations & $2,766,209$ & $2,766,209$ \\
\hline Customer-radiologist Pairs & 44,159 & 44,159 \\
\hline R-squared & 0.182 & 0.181 \\
\hline
\end{tabular}

Robust standard errors in parentheses are clustered by customer-radiologist pairs Model includes a constant term and covariates not reported

$$
\text { *** } p<0.01,{ }^{* *} p<0.05, * p<0.1
$$

